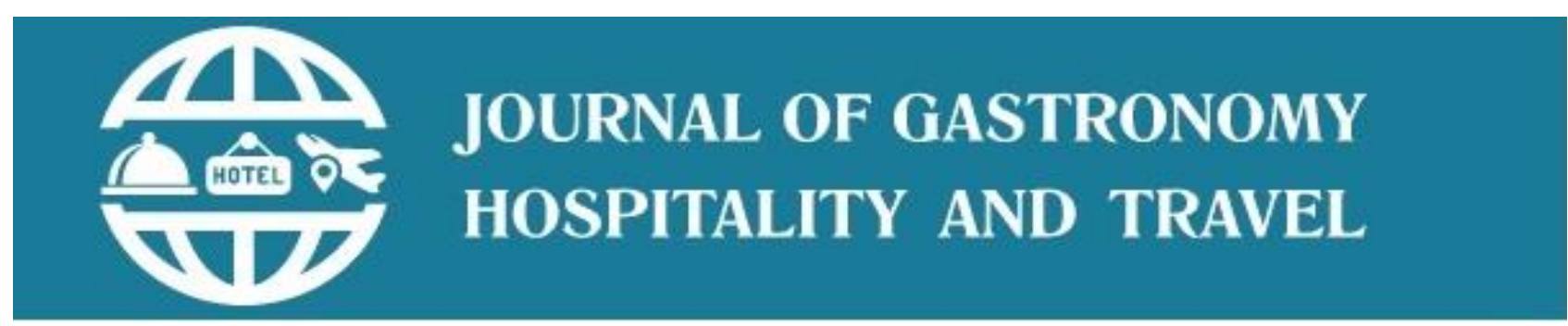

ISSN: 2619-9548

Journal homepage: $\underline{w w w . j o g h a t . o r g, ~}$ http://dergipark.gov.tr/joghat

Journal of Gastronomy, Hospitality and Travel (JOGHAT)

2020 - Volume: 3 Number: 1

Page: $30-41$

Received:06.05.2020

Revised:01/06/2020

Accepted: 03.06 .2020

\title{
Research Article \\ AN ETHNOGRAPHIC INQUIRY TOWARDS 'HARE-RAMA HARE-KRISHNA' RELIGIOUS TOURISTS FOOD CONSUMPTION HABITS WHILE ON A HOLIDAY IN INDIA
}

\author{
Mayukh DEWAN ${ }^{1}$ (orcid.org/0000-0003-0219-1050) \\ SCHOOL OF HOSPITALITY, TOURISM AND EVENTS (SHTE). \\ Faculty Of Social Sciences And Leisure Management (FSLM). \\ Taylor's University, Malaysia
}

\begin{abstract}
Food functions as a medium through which we encounter the world. We consume food based on our society's paramount attitudes towards nature, religious beliefs and nutritional benefits rather than just according to our needs. In this research, the author studied a group of Hare Krishna tourists belonging to ISKCON religious movement of Hindu religion. There are several studies done on the western vegetarian groups based primarily on their ethical, environmental and health-based vegetarian food habits but not many studies on the food consumption behaviour of religious tourists, especially on the Hare Krishnas' during a holiday. This under-represented and under-researched group's struggles and behaviour patterns will help us understand other divergent groups of vegetarians and vegans from across the world and help sensitise the tourism industry to this large group of intermingled and often confusing group of people. This ethnographical, qualitative research is focussed on reflexively studying the Hare Krishna religious tourist's comprehension and interpretation of vegetarianism and the factors which influence their holiday destination choice. The author further strives to understand what happens to the religious food values of a Hare Krishna follower while making food choices during a holiday and whether these tourism experiences influence or transform the religious food values of this group. Food is taken to be a purely functional and supporting resource to tourism and as such tourist's food consumption behaviour and patterns are largely ignored and neglected in tourism literature. In this research, the author adds to the limited body of knowledge of vegetarians based on their religious beliefs along with revealing the reasons, visible and invisible cues this group exhibit and are engaged in while planning their holidays and food choices.
\end{abstract}

Keywords: Vegetarian, Hinduism, Hare Krishna, ISKCON, Religious Tourism, Ethnography.

\section{INTRODUCTION}

Food functions as a medium through which we encounter the world. We consume food not just according to our physiological needs but according the needs of our society (Stiles, 1998). In other words, it means that we consume foods based on our society's predominant attitudes towards nature, religious beliefs and nutritional benefits (Majumder, 1972). This expectation comes from the society in which we have been brought up in. A tourist going to a destination for leisure or religious purposes may behave differently to those who visit a new destination for work or other professional commitments. This change in eating habits would be of profuse interest to an ethnographer to study how the culture and religion influences a person's food habits. In Wolcott's (1987) opinion only an ethnographer can try and make sense of a culture by acting upon it. Most of the food consumption studies are mainly interested in unearthing the elements of various food consumption behaviours, including liking, preference and intake (Mak et al., 2012). Mak et.al. (2012) further add that there is a deep interlink between our food choices and cultural and religious influences, socio-demographic factors, our food-

\footnotetext{
${ }^{1}$ To cite this document: Dewan, M. (2020). An Ethnographic Inquiry towards 'Hare-Rama Hare-Krishna' Religious Tourists Food Consumption Habits While on a Holiday in India, 3(1), 30-41. DOI: 10.33083/joghat.2020.28

Corresponding Author: Mayukh.Dewan@taylors.edu.my
} 
related personality traits, past experiences and other motivational factors in tourism. While looking at past literature, insufficient studies have focused on the tourist behaviour based on their religious beliefs and food choices. This gap in research needs to be filled as tourism and hospitality providers can engage with this group of tourists and provide tailor made packages for them, thereby adding another source of revenue for them. Hare Krishnas' belong to ISKCON (International Society of Krishna Consciousness) which is a relatively newer religious movement from the Vaishnava sect of Hinduism. They have gained prominence in the west and have followers from all parts of the world. These devotees are a part of the movement because of various reasons ranging from animal rights, environmental protection and health reasons along with spiritual and family reasons.

The researcher belong to India which is a very vegetarian friendly country and killing animals or taking life from nature is a taboo (Gupta, 1999). As a meat eater since birth he has grown up in a country where nearly a third of people are vegetarians (Censusindia.Gov.In). Many of his extended family members are religious vegetarians, some of whom are Lord Krishna followers too. When he travels with them to different destinations, he has to spend a lot of time deciding on where to go based on whether we would get the right type of food for the family. This uncomfortable feeling of decision making gets compounded with the fact that we sometimes travelled to foreign countries which had its own norms, a different language and maybe a completely different perspective towards their food habits. Questions like 'will we get the right type of food' and 'the right cooking and food procession methods' in the new country or city was always going through his mind. In this regard, he observes the behaviour of Hare Krishna vegetarian tourists in India to unearth the food consumption and travel behavoiur of such deviant groups and argue the importance of the growing vegetarian and vegan groups in the future of tourism in Asia. This paper aims to present a case study of the ISKCON tourist's food and tourism habits and guide the industry towards adapting to and providing for similar vegetarian tourists in the future.

\section{LITERATURE REVIEW \\ 2.1. FOOD CONSUMPTION, RELIGION AND TOURISM}

Consumption of sights, sounds, customs, culture, religion, food and beverages are all socially constructed essential parts of a tourist's experience on a holiday as nearly every tourist consumes food in a restaurant, fast food joint or street markets in a tourist destination (Cohen \& Avieli, 2004). Food is seen as a gateway or an entry point for a tourist into a new destinations culture and lifestyle. “...it allows an individual to experience the 'Other' on a sensory level, and not just an intellectual one" (Long, 2013, p.195). Conventionally food is understood to be a 'supporting resource' to tourism destination's appeal (Godfrey \& Clarke, 2000). Bessiere and Tibere (2013) explains that "food plays a purely functional role for some tourists and nutrition is fringe of the main purpose of the trip for example pilgrims, for whom eating and drinking remain first and foremost a means of recovering and recouping their strength before getting back on the road. For others, food products are perceived as important for the image and reputation of the locality, but less so than cultural or technological sites, seen as more attractive" (p. 3421).

Existing studies show that tourist food consumption research has been undertaken mostly related to local food consumption patterns (Kim et al., 2009; Ryu \& Jang, 2006; Torres, 2002), food service (Nield et al., 2000; Sheldon \& Fox, 1988), tourists gastronomic experiences (Kivela \& Crotts, 2006, 2009), food as special interest tourism (Ignatov \& Smith, 2006) and tourists food preferences (Chang et al., 2010; Torres, 2002). The missing link here is that food consumption behaviour and neophobic and neophilic food behaviour is focused towards the western world studies and a vast economically rising east is side-lined and ignored. With a growing vegetarian movement across the world comprising of vegans, lacto-vegetarians, ovo-vegetarians, Buddhists, Hindus and Jains, the hotel industry cannot choose to ignore the financial clout that this growing group of tourists exert. The consumer seems to be skewing towards meat avoidance due to various reasons like health, animal rights, environmental concerns and religious concerns. Tapping into and providing for this growing group would be the right step for the hotel and tourism industry.

According to the social construction of reality theory, tourists from a particular socially constructed cultural and religious background like ISKCON will be dictated by their sect (internalised) on what they can and cannot eat (Berger \& Luckmann, 1991). These values and restrictions shape their ultimate choices of food and travel. The tourist's religious background also dictates foods which are acceptable and unacceptable along with cooking and cleaning styles to be used. For this study the 'religious tourists' are defined as tourists who make a journey primarily motivated by their religious needs, visiting religious temples and cites as a part of their 
main plan but also visit family and friends along with tourist destinations during their free time (Vukonic, 1996; York, 2002).

\subsection{FOOD IN HARE RAMA HARE KRISHNA SECT (ISKCON)}

The Hare Krishna vegetarian religious movement was established in the mid-twentieth century by A.C. Bhaktivedanta Swami Prabhupada (Brooks, 1989, 1992). They fall under the Vaishnavism sect of ancient India and see God primarily in the form of Lord Krishna, Lord Rama or Lord Vishnu (Rosen, 1992). Entering this sect, the followers refrain from consuming meat and alcohol along with staying away from gambling and sex outside of marriage (Rochford, 1995; Judah, 1974).

Milk and milk products like yoghurt, butter and ghee are consumed but should be from free range cows that are not pregnant and whose calf has been fed first before they take the excess milk for consumption. They do not consider factory farmed cow's milk or milk obtained from intensive farming methods as good. Their belief stems from the fact that anything which can be consumed without killing or harming the animal is considered good (Flood, 1996). In fact milk is considered as one of the highest forms of vegetarian foods falling under the Sattvic (good) category (Pattanaik, 1996). The food restrictions of this group are stricter than other denominations of Hinduism as there is a higher significance towards the right type of food consumed by them so as to provide them with good health and good worship. Food items like alcohol, tea, coffee, onions and garlic and mushrooms are avoided as they are seen to hinder the spiritual growth of the follower. They objectify their religious beliefs by consuming butter, cheese and yoghurt along with sugar, honey, herbs, spices, fruits, nuts, grains, pulses, beans and most vegetables (Nath, 2010).

\section{METHODOLOGY}

According to interpretivist thought, reality is subjective and influenced by the context of the situation, namely the individual's experience and perceptions, the social environment, and the interaction between the individual and the researcher (Ponterotto, 2005). The interpretivist constructivist ontology says that knowledge is relative, and that they exist in multiple mental constructions. Reality may be local or specific and may be constructed or co-constructed with the respondent (Guba \& Lincoln, 2005). Guba (1996) also argues that multiple realities exist and are dependent on the individual. The researchers relativist ontological beliefs assume that reality as we know it is constructed inter-subjectively with him and the Hare Krishnas together through the fluid and changing meanings and understandings developed socially and experientially. In this research the reality in which the Hare Rama tourists' live may be different from the researcher but he has an affinity towards understanding their reality due to his closeness and overlapping understanding of food and society similar to them. This co-creation of reality is what makes the interpretivist approach worth using. As researchers, we make meanings of what has been said to us; but these meanings are heavily influenced by the social and experiential life which we have lived in (Dewan, 2018). Constantly reflecting on his own identity over the course of the research so as to be reflexive in his analyses, being a Hindu, Indian, Hindi speaking male gave him a distinctive insider perspective of the Hare Krishna devotee's words and actions as he was aware of many of the obvious terms, habits and nuances of a Hindu religious person. Semi-structured qualitative interviews were conducted as one of the methods of data collection along with participant observation, fieldnotes and memoing during the research. However, the following results are only based on the thirteen in-depth interviews. The profile of the respondents is elaborated in the analysis section below.

\section{ANALYSIS}

The ethnographic participant interactions with this religious group had been ongoing since four years but the bulk of the interviews and fieldnotes were collected over a period of one and a half month in July and August 2017 in New Delhi and Vrindavan in India.

\subsection{PARTICIPANTS PROFILE}

The researcher met Hare Krishna devotees in Malaysia as well as in India from all walks of life and economic backgrounds during the course of his research. His initial interaction was with senior Brahmacharis members of the ISKCON community. This difference between the Brahmacharis, Ghrast and regular devotees was not known to him and he always assumed that the robes worn were just a part of their lifestyle. 


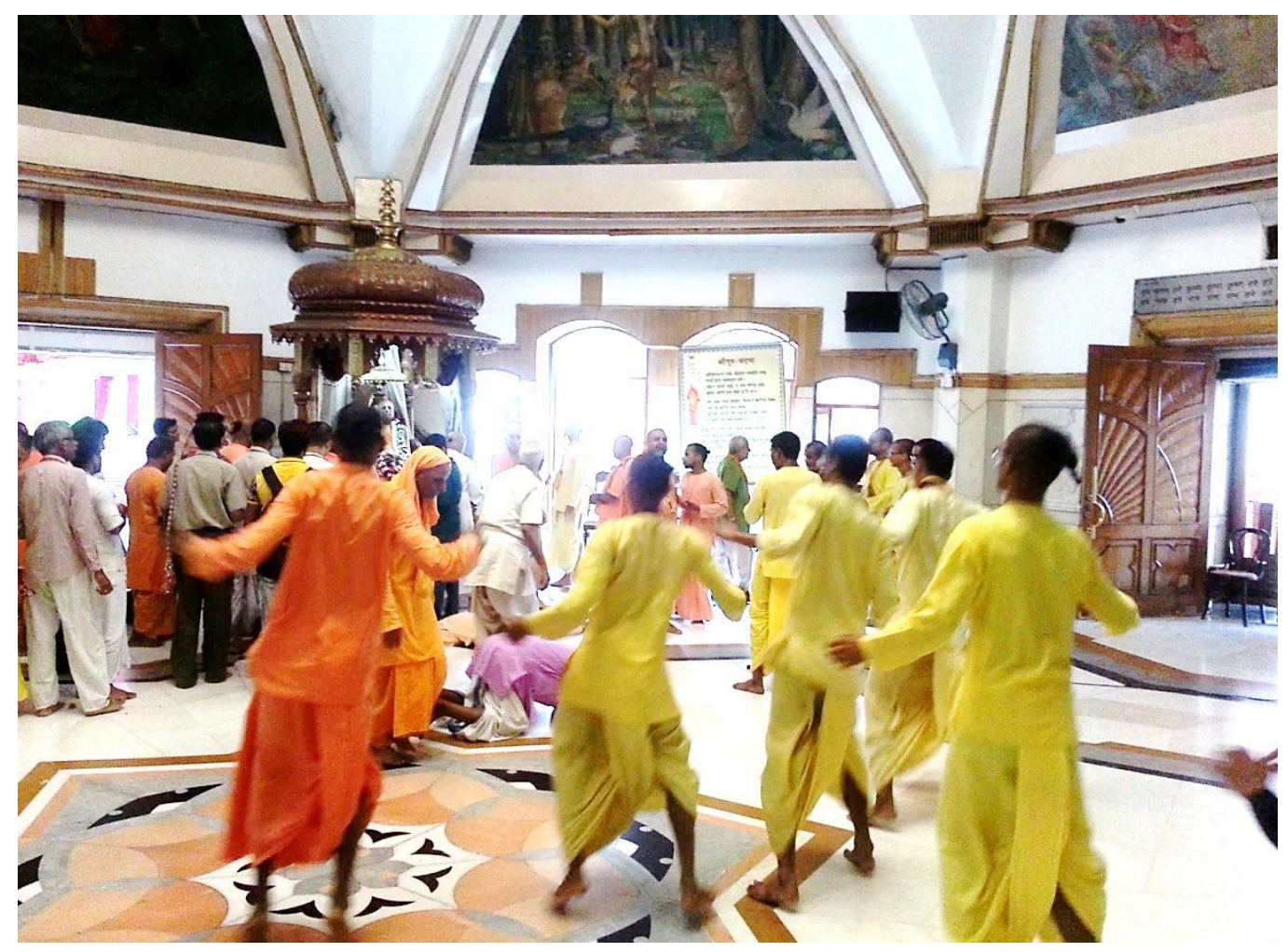

Figure 1: Singing and dancing Brahmacharis in the New Delhi temple. Source: Photograph by researcher.

Most of the Brahmacharis seen in the temple were usually younger (though there were quite a few elderly Brahmacharis too) and were always at the forefront of all the activity, especially the frenzied singing and dancing which happens every so often when the prayers start every few hours during the day (Figure 1). These young men were in red robes called Dhoti Kurta (long traditional men's garment and loose Indian shirt) with shaved heads and carrying their prayer beads around their neck (Figure 2). This group of devotees were initiated into the ISKCON philosophy and stayed unmarried and celibate.

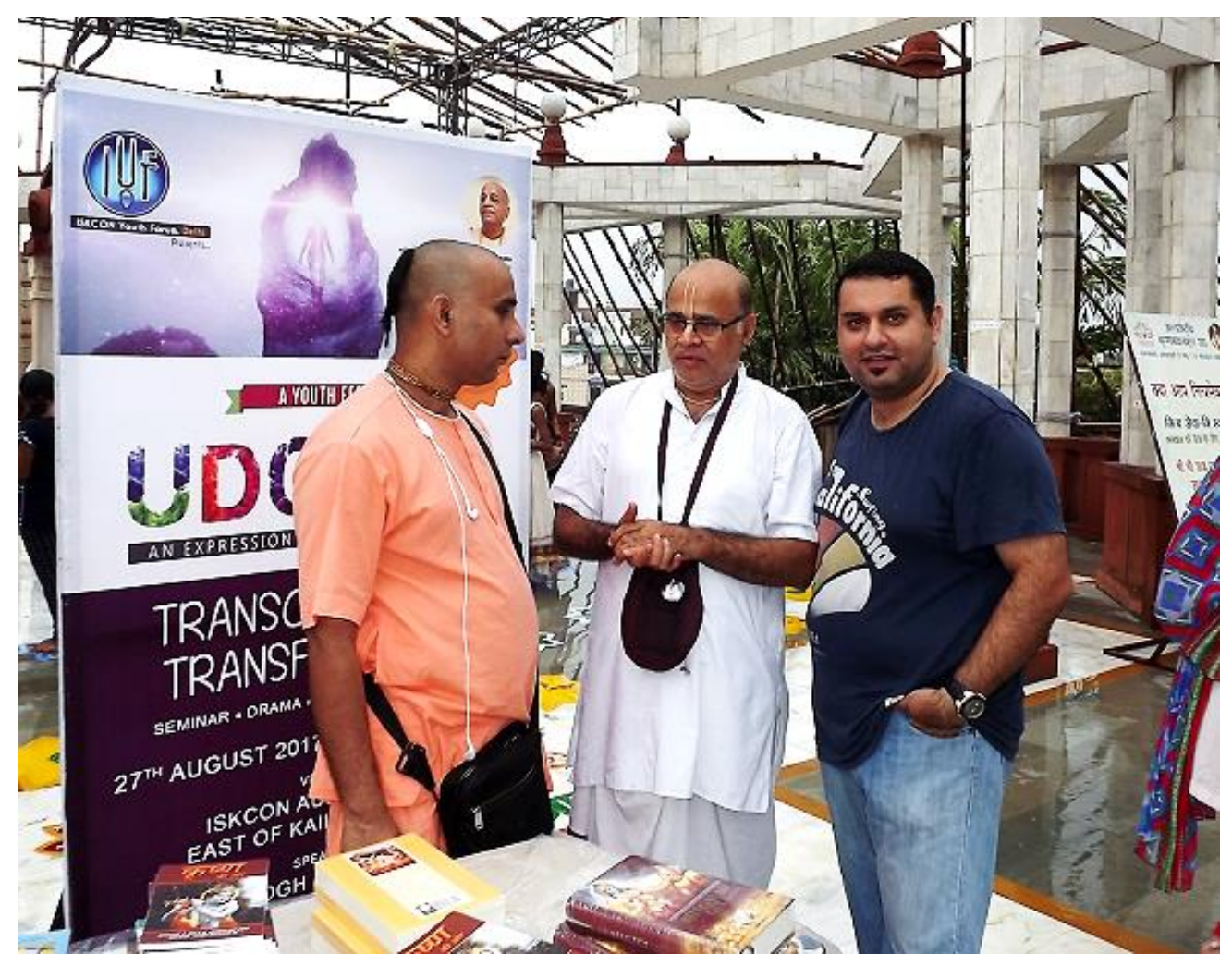


Figure 2: A Brahmachari, a Ghrast and a regular Hindu (researcher). Source: Photograph by researcher.

The second group of devotees were the Ghrast devotees. These were usually wearing white robes but occasional colourful Kurtas were also worn. These were initiated devotees but were married and had children. The third group of devotees visiting the temples were regular Hindus who visited the temple for religious or other purpose but were not specifically devotees following Lord Krishna or the ISKCON philosophy only. The above photo (Figure 2) was taken on the first day of visit to the New Delhi ISKCON temple. The photo shows the researcher standing next to a Brahmachari and a Ghrast devotee (researcher's gatekeeper).

For the in depth interviews the researcher interacted with males and female vegetarian tourists from across the world from as far as Uruguay, Brazil and USA in the Americas, Russia and Ukraine in Europe and from various towns in India. The youngest devotee interviewed was a Ukrainian in his late twenties and the oldest devotee interviewed was a fifty seven year old lady from Uruguay who was a Hare Krishna devotee since thirty years. The international devotees varied in their background and profile too. On one end there were regular earning devotees from Brazil, Russia and India and on the other there were Brahmacharis who had renounced the worldly pleasures and were living in the temple ashrams. On one hand there were businessman and housewives and on the other hand there were retired US Navy soldiers.

\subsection{UNDERSTANDING OF HARE KRISHNA FOOD}

The Hare Krishna philosophy aims to push its devotees to attain spiritual and personal nirvana (highest spiritual state of peacefulness and pureness of the mind) by externalising their actions and food habits (Berger \& Luckmann, 1991). Their food habits are primarily vegetarian in nature with all food in Hinduism falling in the various classifications of goodness (Sattvic), passion (Rajastic) and ignorance (Tamsic). The Hare Krishna devotees primarily consume foods from the Sattvic group of foods. They also reject some types of vegetarian food items like mushrooms and red lentils. Onion and garlic are strictly avoided but not completely rejected.

If you eat garlic, onion or meats....you will have to leave it to come towards Krishna Consciousness. By garlic and onion it means that these are tamsic parvarti foods (denoting a class of foods that are dry, old, foul, or unpalatable, and are thought to promote pessimism, ignorance, laziness, criminal tendencies, and doubt). They are not bad for health but they increase your simulation (Indian male, late 50's).

So onion and garlic they come under tamsic because they lower down your consciousness. You cannot be in the higher consciousness (Indian male, brahmachari, late 20s/early 30s).

Because onion and garlic are not considered vegetarian. They come from the earth but are not considered really vegetarian. It's not good (Uruguay Female, 57).

They are allowed to take only garlic on special occasions when they are unwell and have been prescribed by the doctor to consume onion and garlic for their medicinal benefits.

We can take it as medicine. Only garlic. No onions. Because onions is really serves this purpose of purify the soil. Because if one thing serves to purify something other it's not said that it can also purify ourselves (Brazilian male, early 40s).

The major themes which originated from the interviews as well as the observations are listed below.

\subsubsection{HUMANE/ SIN-FREE/ AHIMSA/ NON-VIOLENT/ CLEAN CONSCIOUSNESS}

Food for a Hare Krishna should be humane in nature. The devotees feel that any food that they eat should not intentionally harm anyone.

It's a kind of mercy, really kind of realisation of this mercy. We can also establish this feeling of friendship with the other living beings. (Brazilian male, early 40s)

Because the world is actually not ahimsa (nonviolence) so we must you know make this microrevolution. It's like if my body can be of some service to others only by not eat or take this kind of violent food if you understand. (Brazilian male, early 40s).

Some of the participants who used to be meat eaters in the past but gave up the meat eating lifestyle for a Hare Krishna lifestyle did it for animal rights and mercy towards animals. 
How the pigs were killed, and I started to think no I don't want to eat. And 4 years later I know HK monk and I started to visit the temple. So when I was 17. I easily joined them (Brazilian female, early $30 s)$.

This thought was echoed by her husband too. He was an ISKCON devotee for nearly twenty years in Brazil and kept that lifestyle even when he moved to France for many years in the early 2000s.

I joined the devotees in 1999 and I was in Brazil and then I lived in a farm, in a community farm. And I became vegetarian before inspired by non-violence yeah (Brazilian male, early 40s).

The devotees strive for a sin-free and clean consciousness in the way they behave as well as the type of food that they eat. A sin free life is a life that the Lord has prescribed for all devotees, in their opinion.

Hare Krishna vegetarianism is based on the fact that, in order to be wanting to love god, in order to know him one has to be free from sins. And sin is doing that which is non-accordance or against the instructions of the supreme Lord (Indian male, brahmachari, late 20s/early 30s).

Because my mind is clean, my heart is clean. It's a nice life. Because I feel so good (Ukrainian male, 30).

Similar to this vegetarian group there are many other groups of tourists who are vegan and vegetarian to various degrees of meat avoidance and they are looking for the right place to eat in their respective tourism destinations.

\subsubsection{SIMPLICITY OF FOOD}

One major tenant of Hare Krishna philosophy is that whatever they do should be simple and not in excess. That includes their lifestyle choices, food habits and even their relationships. In their opinion an excessive lifestyle pulls your soul away from the Sattvic lifestyle towards a more Rajastic lifestyle.

Vegetarian lifestyle is sada bhojan, meaning simple food and simple lifestyle. Not too spicy as it will increase your stimulation. Your dhyan (attention/ awareness) gets diverted somewhere else. (Male, Indian businessman, 50's).

It's a simple lifestyle, first of all and it's also kind because we save the animals. So for me it's a simple way of life (Brazilian female, early 30s).

It has become a habit now to eat a complete simple veg food. Now I enjoy it as a prasadam. It brings a lot of spiritual energy into you (Indian male, late 30s).

\subsubsection{PRESCRIBED IN BHAGWAT GITA}

The main reason for this vegetarian lifestyle is that in the Bhagwat Gita Lord Krishna asked his devotees to offer him this type of food only and nothing else?

$H K$ 's are not just vegetarian. They are different in the sense that they are vegetarians because they believe that there are a set of principles given to us. Krishna says in Bhagwat Gita 'पत्रं पुष्पं फलं तोयं यो मे भक्त्या प्रयच्छति| तदहं भक्त्युपह्तमश्नामि प्रयतात्मन: || 26||', (If one offers Me with love and devotion a leaf, a flower, fruit a water, I will accept it.) (Male, brahmachari, Indian, late 20s/early $30 s)$.

Not taking meat fish or eggs. That's actually prescribed in the Bhagwat Gita (Male early 30's USA).

Because Krishna likes vegetarian. He says in Bhagwat Gita. That if you offer me water, flowers, fruits I will accept if you offer me with devotion. So he just is claiming his diet. So this is the point. This is the main point. There are other points but this is the main one. Because I am following Krishna's lifestyle, we are trying to follow all the aspects of Krishna's lifestyle. (Uruguay Female, 57).

\subsection{INFLUENCES ON HARE KRISHNAS BEHAVIOUR}

In the interviews, along with the observations noted, the main influences on a Hare Krishna vegetarian's holiday destination choices and food choices were family, availability, hygiene and language constraints.

\subsubsection{FAMILY}


Family came up as one of the major influences on a Hare Krishna tourist's behaviour when making a tourism destination choice. It was observed that whenever more than one member of the family was a vegetarian their destination choices became severely restricted towards spiritual retreats rather than on regular leisure based holidays.

My whole family is Krishna conscious. My family, my friends, my cousins they are all devotees. No one is not a devotee. All are HK people... my last holiday was a spiritual retreat in Mayapur, Calcutta. There I don't have to think about. Even if we leave outside the place, we mostly take our food, packed. , there's always arrangement done for us (Indian male, late 20's).

My sons. Yeah. And mom, my sister and my nephews. For my friends, I am in ISKCON more than 30 years so all my friends are here...Actually I myself I don't take so much from hotel. I go generally to houses you know maybe to ISKCON members houses (Uruguay Female, 57).

Yes my elder brother. He is initiated... As a devotee we don't want to go anywhere where you don't get the food items you don't eat. So most of the times we either go to a dham or a religious place. In case of a non-religious place like I said we take our cooking items with us (Indian male, late 30s).

\subsubsection{AVAILABILITY}

One major influence on the Hare Krishna devotee's tourist destination choice is the availability of Hare Krishna (Krishnatarian) food. After a lot of intense clarifications from various devotees who mentioned this word, the researcher came up with the below detailed definition.

A Krishnatarian meal is one which is cooked using fresh, vegetarian ingredients (sans onion, garlic, red lentils or mushrooms) and milk products which is cooked by a Krishna conscious individual who cooks for devotion instead of for profit, and offered to Lord Krishna before it is distributed or consumed by an individual.

If a devotee has problems accessing this type of food or if an ISKCON temple is not in the vicinity of the tourist destination, it causes a lot of discomfort and issues for the Hare Krishna tourist.

The problem is when we are travelling in a journey. Taking the taxies and the planes and the trains .... So we cook something and carry with us or we buy around. We go to vegetarian restaurants, but this is not a habit or something. It's when there is no choice (Uruguay Female, 57).

In the US it's all the more difficult than in India... there are bakeries but the problem with the bakeries is that most of them use eggs in their product and so it's kind of dicey...often times let's say I want a package of cookies, I'll look for the ingredients and make sure there are no eggs (Male early 30's, retired US Navy solder USA).

If we plan a holiday, 2 or 1 day before I start to cook. We all travel with our meals ... as a wife for me the great problem is the food. I need to plan it, what I need to buy, what I need to cook for me it's how to cook is a problem (Brazilian female, early 30 s).

\subsubsection{HYGIENE/ CROSS CONTAMINATION}

One important issue troubling the Hare Krishna tourists is their feeling of outside food to be unhygienic. The first interpretation of food not being hygienic is it literally not being cooked or served in proper sanitised kitchens and using clean equipment.

In the kitchen there in their guest house around Gangotri (town in the Himalayas where holy river Ganga originates) we could see that they were moving in the kitchen in shoes which we do not even use, we cannot even think of. they're using washroom buckets inside the kitchen which was very scary for us...cannot enter inside with shoes, you have to have your hair covered... if you drop anything on the floor you have to wash it, if anything touches your feet, you cannot use it. If any hair falls on the food, it cannot be offered (Male, brahmachari, Indian, late 20s/early 30s).

Another interpretation of food not being clean was the literal hygiene standards of the cook as well as his inner cleanliness. By this the devotees meant that when a person cooks food in a restaurant he cooks for his personal 
economic growth i.e. salary. This is not considered 'hygienic' or 'Krishnatarian' food as the Hare Krishnas consider food to be pure only when the person cooking the food is cooking for Lord Krishna in his heart.

If there is no temple then I take fruits because food outside I don't know who made it (Ukrainian male, 30).

We are very restricted about the food habits hence we don't try it in a non-devotee restaurants (Indian male, late 30s).
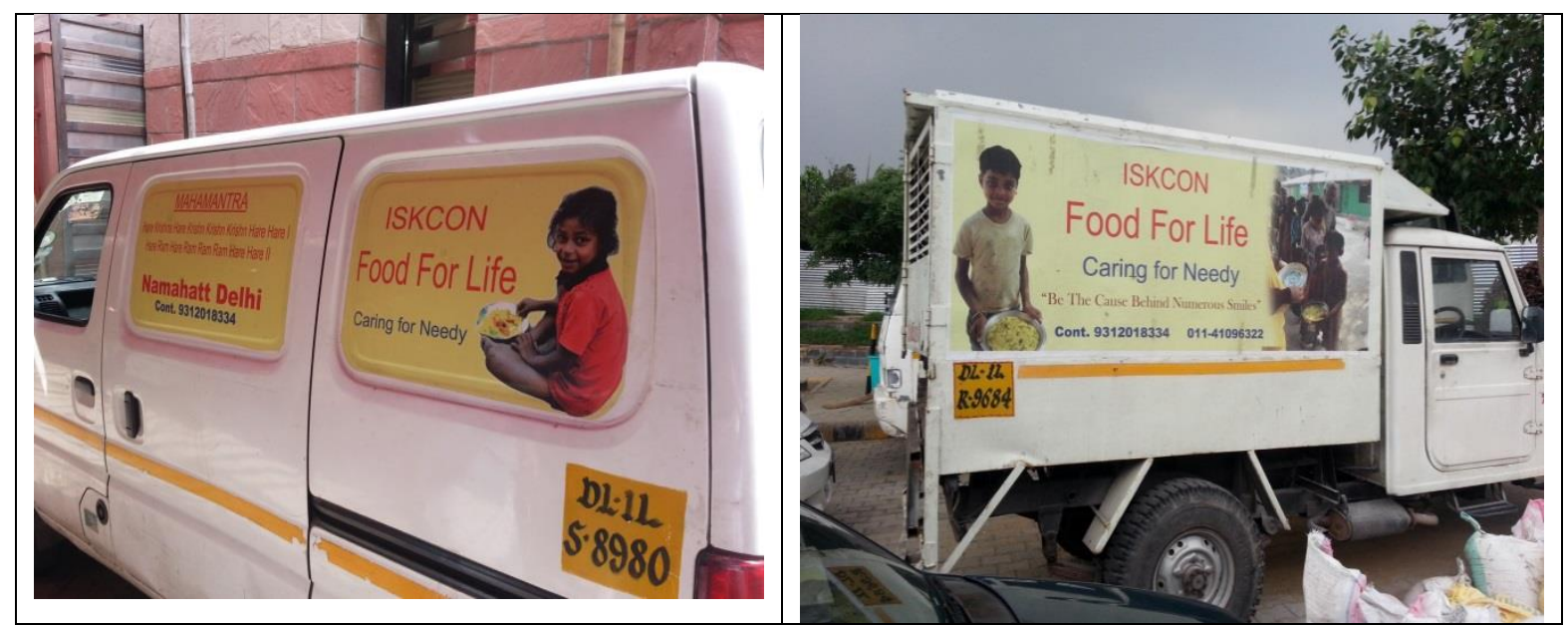

Figure 4: Food for Life Vans picking up and dropping food at various ISKCON temples across Delhi. Source: Photographs by researcher.

This is a very complex scenario to understand as most of the cooks in the temple kitchens as well as in the 'Food for Life' programme (Figure 4) is paid a salary but are also devotees of Lord Krishna.

\subsection{CHANGING VALUES}

The researchers bservations were focussed on the opinion and values of the Hare Krishna devotees while they were on a holiday. The below three behaviour were evident in the participant devotees during the interviews.

\subsubsection{RELAXING OF VALUES/ FOOD NEOPHILIA/ BREAKING THE RULES}

Some of the Hare Krishna vegetarians were seen to be relaxing their values and were willing to accept food in regular restaurants some of which were serving non-vegetarian menu items as well. A young businessman tourist who was interviewed in Vrindavan was willing to visit restaurants when there was no 'Krishnatarian' food available for him. When enquired about what he does when he is travelling with non-devotee friends he showed a little discomfort while answering but was open to sit in any restaurant as long as he got something which he could consume.

If I am going with someone or you I will think about can we manage totally? So that he also not feel bad and I also get my way. I'll think about them...but there is something which doesn't contain non veg or onion garlic...e.g. rice, curd etc. I'll find a way to fulfil my stomachs desires... even God will also help me, after all he is our parent (Indian male, late 20's).

This feeling was echoed by another participant married Brazil woman in her early thirties. She too was willing to share meals with friends and family in regular meat serving restaurants as long as she got a vegetarian or vegan option for herself. Similar answers were received from her husband as well who was interviewed separately.

First of all I need to know if there is a vegan or vegetarian option in the menu because otherwise everyone is eating and you are completely sitting. So before I was very radical, no I don't want to go. But today I am more open. So if there is a vegan or vegetarian option for me so OK, I don't mind if they are eating meat or eggs but I need at-least one option. It's very hard to find (Brazilian female, early 30 s). 
Yeah. Several times I was with my friends in Brazil that take meat and we are were together in a restaurant. I take you know polenta or pizza or I don't know what (Brazilian male, early 40s).

A devotee confided that he had actually consumed vegetarian foods containing onion and garlic on multiple occasions. This neophilic discretion was done for his hedonic pleasures in the case of him eating the vegetarian McDonalds burger in Mumbai or for convenience as was evident when he travelled from Kathmandu to Delhi by bus and had a curry with onions and garlic.

I certainly wouldn't eat out in a pub or anything like that...I had the vegetarian McDonalds food. That was in Bombay (Mumbai). Yeah the other day I came from Kathmandu to Delhi by bus (very long way) which was rough... I ordered some Chana masala. It came with some onions on top. So I just scooped it out. I just minimised the amount of onion and garlic (Male early 30's, retired US Navy solder USA).

\subsubsection{CONSTRICTING OF VALUES/ FOOD NEOPHOBIA}

On the other end of the spectrum, the other devotees were seen to be tensing up their values and were shunning the commercial restaurant industry, even the ones which were serving vegetarian foods. Usually the neophobic tendencies were more evident when trying out new restaurants and with the older generation of devotees who were in the Hare Krishna society for a longer period.

I'll tell them what I want but I will not try new cuisines. This is because I don't know the masalas (spice blend) used in it, using the same serving spoon as non-veg items etc... I don't even try such food... I'll look for a Vaishnav dhaba (vegetarian eating roadside places/not high-end places). There will tell them to wash the frying pan and then ask them what they can cook without onions. I get that made and ask about the masalas because there are some masalas which have onion and garlic in them (Indian male, businessman, 50's).

Yeah we go to vegetarian restaurant or something. No, I wouldn't go to a restaurant serving meat. They mix everything in the kitchen (Uruguay Female, 57).

\subsection{PHYSICAL DISCOMFORT}

Physical discomfort of the participants when consuming vegetarian foods containing garlic and onion was another often talked about subject during the interactions with the Hare Krishnas.

You know today for me garlic and onion it's like an ingredient I can't take it. It's not a choice. I have a problem with my digestion. When I take something with onion, I feel bad 5 minutes after that. It's not psychological, it's physical. You just take because you have no choice. we are so hungry and then like 2 days before we were on the aeroplane coming to India and in the flight we took something with onion, it was so bad (Brazilian male, early 40s).

\subsection{TOURISM'S IMPLICATION ON VALUES}

A main part of the observations was also to see whether new tourism experiences influences or transforms the religious food choice values of the Hare Krishna devotees.

\subsubsection{VALUE TRANSFORMATION-POSITIVE PUSH}

It was observed that many of the participants who had travelled a lot for their leisure or spiritual tours were quite open to trying new food items and new restaurants as a result of their tourist activities. It was also obvious that the more they travelled internationally and interacted with devotees from non-similar backgrounds as themselves, the more open they got in accepting newer cuisines and restaurants.

Yes it's no problem as long as it is vegetarian. I'll trust you first as I think you will offer me vegetarian food... As long as it is vegetarian and no onion and garlic (Indian male, late 20's).

Oh yeah definitely. I just grew up eating different types of cuisines. Japanese, Chinese, Indian, Mexican. So I was always open to trying new I mean yes, yes, yeah. I would. Definitely, definitely (Male early 30's, retired US Navy solder USA). 
Even a Brahmachari devotee who was well read (college graduate) and travelled extensively with non-devotees was quite open to trying out new cuisines and food products. This could be attributed to his meeting young college students regularly (he was a youth counsellor) and also his young age.

Yeah. this happens, not just travelling but there are people in ISKCON from different parts of the world... obviously everyone likes change... that was OK, having once a month is OK (male, brahmachari, Indian, late 20s/early 30s).

Similar answers were received from Ghrast (married) devotees who were former Brahmacharis.

Yeah it is impossible not to try new food because you don't get (Brazil food) ha ha, and you know Indian food is so diverse so it's impossible not to something new...yeah. In Italy and France now we have a lot of new vegetarian vegan restaurants... But first of all we visit ISKCON restaurant. Not anymore in France but in Italy in many cities they are ISKCON. (Brazilian male, early 40s).

Yeah. Why not. If it is pure vegetarian, why not. Because you are an international society so they have devotees from all parts of the world. So you see we already tried everything... we are trying all kinds of food. Not just Indian food (Uruguay Female, 57).

\subsubsection{VALUE TRANSFORMATION-NEGATIVE PUSH}

On the other end of the spectrum, some older devotees were not willing to try new cuisines or food items in their holiday destinations. They would sacrifice their hunger but detest new tastes or cooking styles as a result of their holiday experience.

There are many times that I don't eat. if I don't get any north Indian food I'll at least get bread, milk or curd or sweet corn, we'll use (eat) that. (Indian male, businessman, 50's).

Even some of the relatively younger devotees were seen to be constricted in their food choices and do not get relaxed even if they visit the destination for a second or third time. One international devotee stayed in Kolkata temple for quite a year before shifting to the New Delhi temple. Even with such a long holiday experience he still felt very uncomfortable sitting with me for a chat in a small vegetarian restaurant outside the temple.

New? No. my gurumaharaj will not be happy. I eat only prasadam, nice prasadam. No no no. it's possible to take after I take, I have problem. I have problem with my spiritual life. It's no good because after next day I chant my Japa my mind no good. My spiritual life maybe stop. It's very very very bad. So I don't take (Ukrainian male, 30).

\section{REVIEW OF THE FINDINGS}

The Hare Krishna tourists recognise their vegetarian food to be simple, sin free and humane food that has been prescribed in the Bhagwat Gita. The major influences that impact a Hare Krishna tourist's behaviour when making a holiday destination choice are family, availability of Krishnatarian food and hygiene (not crosscontaminated with meat items). We can safely deduce that similar behaviours and attitude can be attributed to other vegetarian groups like vegans, ovo-vegetarians and lacto vegetarians.

While making food choices during a holiday, food neophilia caused many of the younger devotees to relax their values and accept non-Krishnatarian vegetarian foods and even sit in non-vegetarian restaurants when accompanied by friends. The older devotees usually were more constricted by their food values and had higher neophobic tendencies along with physical discomfort if accidently ingesting onion or garlic.

The tourism experience positively influences and transforms the religious food values and practices of many of the vegetarians and they really looked forward to trying out newer cuisines and cooking style as long as the food was cooked with the right ingredients and motivations. This should be seen as a very positive trend and the hospitality and tourism industry should aim to cater to this growing market segment. The hospitality industry of the future can learn from and adapt to the food preparation styles outlined in this chapter, thereby increasing their market value and stay relevant with the changing consumer preferences.

\section{LIMITATIONS}

Gaining access to the field of study is one of the toughest stages in ethnographic research (Dewan, 2018) and it was the same here too. Several limitations came up during the data collection stage. Even with the cultural, religious and language affinity to the devotees it was as if the researcher could never be a complete insider or 
native nor an outsiders or non-native; rather, he kept jumping between these roles in the process of the ethnographic journey (Dewan, 2018). The researcher made sure that he distanced his work from positivist terms like validity, generalisability and reliability and attempted trustworthiness, credibility, dependability and confirmability of his work (Dewan, 2018). While conducting the ethnographical fieldwork, his focus was on the quality of relations that he built with the participants and interviewees and also to accept them with their subjective views, voices and predicaments.

\section{CONCLUSION AND RECOMMENDATION}

Due to the lack of studies focusing on the food consumption patterns based on Hindu religion and cultural needs of tourists, this study contributes to the theoretical body of knowledge by providing an exploratory study this niche vegetarian group. Practical contributions include assisting countries looking for newer niche markets and newer clients to use this research to appreciate the perspectives and attitudes of this vegetarian divergent group. This in-turn can add to the economic value addition to the tourism and hospitality industry by making them understand and adapt to the changing food consumption patterns across the world. From a management perspective, tour operators and airlines and the tourism ministries of countries can use this research to identify and conceptually design tailor-made packages for similar vegetarian groups to increase their customer base in generating more revenue.

Future researchers can look at the role of various tourism and leisure notions while trying to explain the vegetarian tourist's food choices. The vegetarian tourists intrinsic motivational factors compared to their chosen destinations characteristics would help us understand the vegetarian tourist's food choices better. This research would be useful for the development of effective strategies to develop and shape the future of tourism in Asia by focussing on food habits of the growing vegetarian segments of the tourist market.

\section{References}

Bessiere, J., \& Tibere, L. (2013). Traditional food and tourism: French tourist experience and food heritage in rural spaces. Journal of the Science of Food and Agriculture, 93(14), 3420-3425.

Brooks, C. R. (1989). The Hare Krishnas in India. Princeton University Press: Princeton, New Jersey.

Brooks, C. R. (1992). 'Gaudiya Vaisnavism in the modern world' in Rosen, S. J. (ed.) Vaisnavism: Contemporary scholars discuss the Gaudiya tradition. Folk Books: New York.

Dewan, M. (2018). Understanding Ethnography: An 'Exotic' Ethnographer's Perspective. In: Mura P., KhooLattimore C. (eds) Asian Qualitative Research in Tourism. Perspectives on Asian Tourism. (1st ed.) (pp.185-203), Springer, Singapore

Flood, G. D. (1996). An introduction to Hinduism. Cambridge University Press.

Godfrey, K., \& Clarke, J. (2000). The tourism development handbook: a practical approach to planning and marketing. Burns \& Oates.

Guba, E. G. (1996). What happened to me on the way to Damascus. In L. Heshusius \& K. Ballard (Eds.), From positivism to interpretivism and beyond: Tales of transformation in educational and social research (pp. 43-49). New York: Teachers College Press.

Guba, E.G., \& Lincoln, Y.S. (2005). Paradamic Contrivaeries, contradictions and emerging confluences. In N.K. Denzin \& Y.S. Lincoln (Eds.), The Sage Handbook of Qualitative Research (3rd ed., pp. 191-215). Thousand Oaks, CA: Sage.

Gupta, V. (1999). Sustainable tourism: learning from Indian religious traditions. International Journal of Contemporary Hospitality Management, 11(2/3).

Ignatov, E., \& Smith, S. (2006). Segmenting Canadian culinary tourists. Current Issues in Tourism, 9(3), 235.

Judah, S. (1974). Hare Krishna and the counterculture. Wiley: New York.

Kim, Y. G., Eves, A., \& Scarles, C. (2009). Building a model of local food consumption on trips and holidays: A grounded theory approach. International Journal of Hospitality Management, 28(3), 423-431. 
Kivela, J., \& Crotts, J. C. (2006). Tourism and gastronomy: Gastronomy's influence on how tourists experience a destination. Journal of Hospitality \& Tourism Research, 30(3), 354-377.

Kivela, J. J., \& Crotts, J. C. (2009). Understanding travelers' experiences of gastronomy through etymology and narration. Journal of Hospitality \& Tourism Research, 33(2), 161-192.

Long, L. M. (2013). Culinary tourism. In Encyclopedia of food and agricultural ethics (pp. 1-8). Springer Netherlands.

Majumder, S. K. (1972). Vegetarianism: Fad, Faith, or Fact? The ecological and nutritional aspects of vegetarianism are appraised against the backdrop of the current world scene. American scientist, 60(2), 175-179.

Mak, A. H., Lumbers, M., Eves, A., \& Chang, R. C. (2012). Factors influencing tourist food consumption. International Journal of Hospitality Management, 31(3), 928-936.

Nath, J. (2010). 'God is a vegetarian': The food, health and bio-spirituality of Hare Krishna, Buddhist and Seventh-Day Adventist devotees. Health Sociology Review, 19(3), 356-368.

Nield, K., Kozak, M., \& LeGrys, G. (2000). The role of food service in tourist satisfaction. International Journal of Hospitality Management, 19(4), 375-384.

Pattanaik, A. (1996). Changing trends in dietetics. Ancient science of life, 16 (1), 62.

Ponterotto, J. G. (2005). Qualitative research in counseling psychology: A primer on research paradigms and philosophy of science. Journal of counseling psychology, 52(2), 126.

Rochford Jr, E. B. (1995). Family structure, commitment, and involvement in the Hare Krishna movement. Sociology of Religion, 56(2), 153-175.

Rosen, S. J. (1992). Vaisnavism: Contemporary scholars discuss the Gaudiya tradition. Folk Books: New York.

Ryu, K., \& Jang, S. (2006). Intention to experience local cuisine in a travel destination: The modified theory of reasoned action. Journal of Hospitality \& Tourism Research, 30(4), 507-516.

Sheldon, P. J., \& Fox, M. (1988). The role of foodservice in vacation choice and experience: A Cross-Cultural Analysis. Journal of Travel Research, 27(2), 9-15.

Stiles, B. (1998). Vegetarianism: Identity and experiences as factors in food selection. Free Inquiry in Creative Sociology, 26(2), 213-226.

Torres, R. (2002). Toward a better understanding of tourism and agriculture linkages in the Yucatan: Tourist food consumption and preferences. Tourism Geographies, 4(3), 282-306.

Vukonic, B. (1996) ‘Tourism and Religion', Pergamon, New York.

Wolcott, H.F. (1987). On ethnographic intent. In Spindler, G., \& Spindler, L. (Eds), Interpretive ethnography of education: At home and abroad, 19(1), 37-51.

York, M. (2002). Contemporary Pagan pilgrimages. From medieval pilgrimage to religious tourism: The social and cultural economics of piety, 137-158. 